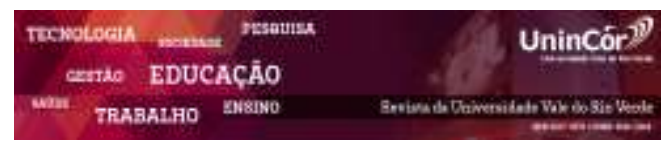

Revista da Universidade Vale do Rio Verde ISSN: 1517-0276 / EISSN: 2236-5362 Vol. 16 | n. 2 | Ano 2018

Rosângela Vidal de Negreiros Universidade Federal de Campina Grande rosangelavn@ufccg.edu.br

Vanessa Cristine Batista de Lima Hospital das Clínicas vanessacriistine28@gmail.com

\section{IMPORTÂNCIA DO ESTÁGIO SUPERVISIONADO PARA O ACADÊMICO DE ENFERMAGEM NO HOSPITAL: compartilhando experiências vivenciadas com a equipe de trabalho}

\section{RESUMO}

O estágio supervisionado é de fundamental importância para o acadêmico de enfermagem, pois esta é uma oportunidade de estabelecer certo vinculo profissional sem que este esteja anulado ao vinculo educacional, tornando-se, portanto, a última oportunidade, durante a graduação, de avaliar os conhecimentos adquiridos, favorecendo e desenvolvendo as habilidades obtidas. Objetivou-se compartilhar a experiência do estágio supervisionado enfatizando a importância do trabalho em equipe no sistema hospitalar. A metodologia decorre do relato da experiência vivida por acadêmicas de enfermagem do Curso de Bacharelado em Enfermagem da Universidade Federal de Campina durante o Estágio Supervisionado II em Enfermagem, no Hospital Universitário Alcides Carneiro (HUAC), durante o $10^{\circ}$ período do curso, desenvolvido no período entre dezembro de 2015 a março de 2016, sob a supervisão direta das enfermeiras do hospital. O funcionamento do sistema hospitalar depende do bom andamento de todos os serviços prestados, no entanto para que haja qualidade nos serviços existe um fator preponderante que é a concretização do trabalho em equipe, é de suma importância que o acadêmico desenvolva competências que favoreça a sintonia do trabalho em equipe, favorecendo para que a assistência seja efetivada de maneira coerente e uniforme, associando as possibilidades propostas pela literatura com a realidade cotidiana da instituição. Conclui-se que o estágio supervisionado valida a graduação em enfermagem, propiciando ao acadêmico o enfrentamento da sua futura profissão estabelecendo artifícios para que lide com as inúmeras situações que podem lhe acometer no exercício da enfermagem.

Palavras- chave: Estágio supervisionado. Equipe de enfermagem. Estudantes de Enfermagem. Assistência. Sistema hospitalar.

\section{IMPORTANCE OF THE SUPERVISED STAGE FOR THE ACADEMIC OF NURSING IN THE HOSPITAL: sharing experiences with a work team}

\begin{abstract}
The supervised training is for academic nursing the opportunity to establish professional bond without being annulled the educational bond, settling, so as long as the last chance for graduation, to assess the knowledge acquired during the same, promoting and developing the skills obtained. The objective was
\end{abstract}


to share the stage of supervised experience emphasizing the importance of teamwork in the hospital system. The methodology stems from the report of the experience by the academic nursing from the Federal University of Campina Nursing Degree Course during the Supervised Internship II Nursing at the University Hospital Alcides Carneiro - HUAC during the 10th period of the course, in the period between February and July 2015, under the direct supervision of hospital nurses. The operation of the hospital system depends on the smooth running of all services provided by it, and yet there is quality in services there is a predominant factor is the realization of teamwork, it is critical that the academic develop skills that favors Work tune in team, favoring so that assistance is effective in a consistent and uniform manner, combining the possibilities proposed by the literature with the everyday reality of the institution. Concluded that the valid supervised training graduation in nursing, providing the academic coping with their future profession by setting devices to deal with the many situations that can affect you in the practice of nursing.

Keywords: Clinical clerkship; Nursing, team; Students, nursing.. Assistence. System hospitalar.

Recebido em: 14/01/2018 - Aprovado em: 24/07/2018 - Disponibilizado em: 15/12/2018

\section{INTRODUÇÃO}

O estágio supervisionado (ES) favorece a formação do aluno enquanto vínculo educativoprofissionalizante, sendo considerado uma experiência relevante nas situações de aprendizagem por relacionar teoria e prática. Exige do discente a realização da práxis em cada atividade desenvolvida, gerando o aprofundamento do fazer reflexivo e consequentemente a promoção da qualidade da intervenção, resultando numa aprendizagem significativa por conta do aprimoramento, desenvolvimento de habilidades e competências discentes (MARRAN; LIMA; BAGNATO, 2015).
Segundo Melo, Negreiros, Macêdo (2014, p.4):

Além dos benefícios que o estagiário traz para $\mathrm{o}$ estudante, ele permite um fluxo maior de informações entre a Universidade, os Serviços de Saúde e a Comunidade. Essa troca de experiências entre os três componentes, por um lado, possibilitam que os Serviços e a Comunidade se beneficiarem com a introdução e divulgação de novas tecnologias e educação permanente, além dos estagiários tornarem-se conhecidos pelas instituições empregadoras, futuros mercados de trabalho para os enfermeiros.

O ES em enfermagem é, portanto, fundamental enquanto diretriz curricular nacional, realizado no último período da 
graduação como predisposto no Art.7 da resolução do CNE/CES No 3, de 7 de novembro de 2001 (BRASIL,2001).

O Conselho Nacional de Educação dispõe que na formação do Enfermeiro, além de trabalhar conteúdos teóricos e práticos durante a graduação, sendo obrigatoriedade da instituição incluir o estágio supervisionado em hospitais gerais e especializado, ambulatórios, rede básica de serviços de saúde e comunidades, nos dois últimos semestres do Curso de Graduação em Enfermagem, com a supervisão direta pelos enfermeiros da própria instituição onde o estágio está sendo realizado. A carga horária do estágio deve totalizar $20 \%$ da carga horária total do Curso de Graduação em Enfermagem proposto (BRASIL, 2001).

O estágio supervisionado da Universidade Federal de Campina Grande (UFCG), campus Campina Grande é realizado no Hospital Universitário Alcides Carneiro (HUAC), onde os acadêmicos do $10^{\circ}$ período da graduação devem cumprir uma carga horária de 420 horas.

Tendo em vista a necessidade da prática de estágio em campo hospitalar, o favorecimento de vivências em situação cotidianas é de extrema importância para o acadêmico, pois o coloca frente a frente com a realidade concreta, e assim o prepara para lidar em atuações de diversas competências, enxergando o homem em sua integralidade, complexidade e singularidade. Para a realização deste relato considerou-se compartilhar a importância do estágio supervisionado, no aspecto do trabalho em equipe para prestar uma assistência de qualidade no sistema hospitalar.

\section{MÉTODOS}

Trata-se de um relato de experiência, da vivência do estágio supervisionado II do Curso de Bacharelado em Enfermagem do $10^{\circ}$ período da Universidade Federal de Campina Grande Campus Campina Grande - PB no Hospital Universitário Alcides Carneiro - HUAC, situado no município de Campina Grande/PB, na Rua Carlos Chagas, s/n, no bairro São José do município de Campina Grande - PB, onde as acadêmicas estagiaram 60 turnos, distribuídos em três setores. Setores esses a ala A (cirúrgica), ala D (clínica masculina) e CME. Os setores foram escolhidos por meio se sorteio realizado previamente o início do estágio supervisionado. Este estágio foi realizado no período entre dezembro de 2015 a março de 2016 sob a supervisão direta das enfermeiras vinculadas ao hospital.

\section{]RESULTADOS E DISCUSSÃO}

A enfermagem deve utilizar a Sistematização da Assistência de Enfermagem (SAE) enquanto instrumento de trabalho do enfermeiro, com o objetivo de identificar as necessidades de cada paciente propondo seu atendimento e cuidado, direcionando a equipe nas ações a serem realizadas. Trata-se de um processo dinâmico e que requer na prática o 
conhecimento técnico-científico aplicado a realidade cotidiana da instituição (MENEZES; PRIEL; PEREIRA, 2010).

A equipe de enfermagem tem subsídios para o exercício profissional, afim de que seja realizada uma assistência coerente e uniforme, através de instrumentos de trabalho baseados na literatura ou mesmo nos protocolos operacionais padrão de cada instituição.

As equipes de enfermagem se articulam de maneira benéfica, trabalhando em sintonia, buscando o melhor para o paciente, em geral realizam a divisão das tarefas de modo que não sobrecarregam a nenhum dos componentes da equipe, porém a diferença das personalidades e do modo como cada profissional reage diante das situações se conforma em um fator prejudicial para a aceitação de novas propostas, de implementação do serviço e da educação permanente. A dinâmica das relações humanas possui difícil compreensão e se modifica de acordo com a evolução do processo de trabalho.

O trabalho em saúde fora acometido por grandes mudanças com o avanço cientifico e tecnológico, no que diz respeito à qualificação de métodos diagnósticos e terapêuticos. Porém as dinâmicas das relações humanas no processo de trabalho mantem-se estigmatizado e submetido a estudos que abordam assuntos como conflito, produtividade, dinâmica grupal, liderança (MOURA et al., 2013).

De acordo com Moura et al (2013, p.199):

A enfermagem constituise de um grupo bastante numeroso de profissionais cujas ações desenvolvemse no âmbito coletivo, sendo realizadas por equipes de trabalho que necessitam encadear harmonicamente seus esfor- ços [...] assegurando a continuidade do cuidado de enfermagem aos pacientes internados nos hospitais. Estas características são determinantes para a existência de modelos de organização do trabalho alicerçados na liderança e na atividade profissional dos grupos.

Durante o estágio pode-se observar que surgem inúmeras adversidades para execução dos serviços, isso torna evidente a necessidade de qualidades como a liderança em cada componente da equipe, inclusive no próprio estagiário. O acadêmico torna-se sensível ao exercício profissional em equipe que enfaticamente requer dos enfermeiros expandir suas competências perante suas responsabilidades, consequentemente ampliando seus reconhecimentos.

São atribuições dos discentes de enfermagem durante o estágio supervisionado: Tomar conhecimento e cumprir as normas do estágio; respeitar a hierarquia funcional da UFCG e as resoluções do Conselho Federal de Enfermagem; manter postura ética; zelar e ser responsável pela manutenção das instalações e equipamentos utilizados durante o desenvolvimento do estágio; cumprir as atividades regulares constituídas nas ações realizadas diariamente na unidade escalada, reuniões, realização de planos de trabalho e relatórios de estágios, levantamentos bibliográficos e participação em atividades especificas do hospital; participar de outras atividades correlatas que venham a enriquecer, quando solicitado pelo enfermeiro e/ou docente; cumprir a carga horária semanal designada pelo docente, estabelecidas em escala de revezamento de acordo com as necessidades; comunicar e 
justificar, com antecedência, ao enfermeiro e ao docente, sua ausência nas atividades; manter atualizado a folha-ponto especificando os dias e horas de estágio com assinatura do enfermeiro responsável; o discente deve seguir a escala elaborada pelo docente, em datas préestabelecidas (MELO; NEGREIROS, MACÊDO, 2014).

O aluno participa como sujeito na construção de conhecimentos e não mais como figurante, mediante tais necessidades de mudança, o acadêmico possui conhecimentos próprios, autonomia, da literatura, internet e senso comum, esse último tem fundamental importância para despertar no aluno a necessidade de busca do conhecimento científico, e ainda participar de discussões em grupo (SILVA; SILVA; RAVALIA, 2009).

O estágio supervisionado ainda possibilita ao acadêmico a compreensão da dimensão do cuidado quando inserido como participante do processo de trabalho em saúde, logo, o aluno sente a necessidade de desenvolver saberes que a graduação talvez não tenha suprido, tal como o saber conviver, que remete a competências gerais, para poder atuar nas diversas situações do contexto do trabalho de saúde (BENITO et al., 2012).

A experiência do estágio torna-se enriquecedora não somente na perspectiva profissional, mas traz suas contribuições para a vida do acadêmico, potencializando sua resiliência diante das situações, modificando e elucidando seus ideais através de suas percepções e valores, que podem ser transformados ou moldados de acordo com suas experiências e contatos com profissionais e instituições de saúde e de ensino, constitu- indo um eterno aprendiz, sempre aberto à inovação e designação objetivando a qualidade do trabalho em equipe e da assistência (LIMA et al., 2014).

O trabalho em equipe reflete da comunicação existente entre a mesma, podendo ser sempre melhorada em função da assistência ao paciente, utilizando como pontos favoráveis à interação humana, relação de interdependência, reconhecimento profissional; compartilhamento de informações através da sistematização da assistência de enfermagem e de reuniões em equipe, de acordo com as situações e necessidades (BROCA; FERREIRA, 2012).

Entende-se que o acadêmico que está prestes a acabar o curso de enfermagem, saiba executar competências e habilidades específicas do enfermeiro, agir com atitudes profissionais, apoiados sempre em conhecimentos, porém sem se deixar limitar a ele. Deve intervir de forma eficaz em relação ao sistema de saúde e tudo que aquilo ele pertencer (BENITO et al, 2012).

\section{CONCLUSÃO}

O estágio supervisionado se conforma como o ultimo vinculo do acadêmico e possibilita desde já projeções de como lidar com a vida profissional, articulando as situações cotidianas do serviço. É importante destacar que após a realização do estágio, o acadêmico e quase profissional sente-se mais preparado e aprende a lidar melhor com a vida profissional, as rotinas e a conviver com equipe de trabalho que futuramente este terá que aprender a liderar. 
Compreendeu-se enquanto acadêmicos

que a comunicação e consequentemente a interação da equipe são fatores cruciais para a efetivação do cuidar qualificado, baseado no fazer técnico e científico.

Assim como nas diretrizes curriculares propostas em curso de graduação, debater competências é de total pertinência para o processo de formação do profissional. Sendo assim o projeto pedagógico dos cursos de enfermagem, devem-se basear em constituições filosóficas, conceitos, políticas e metodológicos, a fim de garantir profissionais críticos, dinâmicos, ativos e que possam refletir diante da demanda de trabalho, ter compromisso em assumir os direitos de trabalho e cidadania (BENITO et al, 2012).

Os integrantes da equipe de saúde, principalmente a de enfermagem durante seu processo de trabalho tendem a influenciar um ao outro, devido ao estabelecimento de relações de interdependência, essa influencia, na equipe de enfermagem, pode ser utilizada para favorecer que a assistência de enfermagem, com a consequente criação de vínculo entre a equipe.

Para Broca e Ferreira, (2012) a comunicação tem seu alicerce nas relações interpessoais que se configura a partir da interação, a enfermagem, ciência e arte de cuidar, se dá no campo da interação humana."

Durante o estágio supervisionado o acadêmico deve desenvolver seus saberes e competências, utilizando o trabalho em equipe para contribuir com as equipes, de modo que projete suas práticas profissionais baseadas nas evidencias cientificas e experiências vivenciadas.

\section{REFERÊNCIAS}

BENITO, G.A.V. et al. Desenvolvimento de competências gerais durante o estágio supervisionado. Rev Bras Enferm, Brasília 2012 jan-fev; 65(1): 1728.Disponível em: http://www.scielo.br/scielo.php?script=sci_arttext\&pi $\mathrm{d}=\mathrm{S} 0034-$

$71672012000100025 \& \operatorname{lng}=\mathrm{en} . \mathrm{http}: / / \mathrm{dx}$. doi.org/10.15 90/S0034-71672012000100025.

BRASIL. Resolução CNE/CES $n^{\circ} \quad 3$, de 7 de novembro de 2001. Disponível em: Acesso em: 26.02 2016.

BROCA, P.V; FERREIRA, M.A. Equipe de enfermagem e comunicação: contribuições para o cuidado de enfermagem. Rev Bras Enferm, Brasília 2012 jan-fev; 65(1): 97-103. Disponível em: http://www.scielo.br/scielo.php?script;SILAsci_arttext \&pid=S0034-71672012000100014\&lng=en. http://dx.doi.org/10.1590/S0034$\underline{71672012000100014 .}$.

LIMA, T.C. et al. Estágio curricular supervisionado: análise da experiência discente. Rev Bras Enferm. 2014 jan-fev; 67(1): 133-40. Disponível em: http://www.scielo.br/scielo.php?script=sci_arttext\&pi $\mathrm{d}=$ S0034-71672014000100133\&lng=en.

http://dx.doi.org/10.5935/0034-7167.20140018.

MARRAN, A.L; LIMA, P.G; BAGNATO, M.H.S. As políticas educacionais e o estágio curricular supervisionado no curso de graduação em enfermagem. Trab. educ. saúde, Rio de Janeiro, v.13 n.1, p.89-108, jan/abr. 2015. Disponível em: <http://www.scielo.br/scielo.php?script=sci_arttext\&p $\mathrm{id}=\mathrm{S} 1981-77462015000100089 \& \operatorname{lng}=\mathrm{en} \& \mathrm{nrm}=\mathrm{iso}$. Acesso em 30 Abr. 2015. Epub Dec 12, 2014. http://dx.doi.org/10.1590/1981-7746-sip00025.

MELO, E.C.A; NEGREIROS, R.V; MACÊDO, M.F.L. Manual do Estágio Supervisionado II. Ministério da Educação, Universidade Federal de Campina Grande, 2014.

MENEZES, S.R.T; PRIEL, M.R; PEREIRA, L.L. Autonomia e vulnerabilidade do enfermeiro na prática da Sistematização da Assistência de Enfermagem. Rev Esc Enferm USP, v. 45.n. 4. São Paulo, 2011.

MOURA, G.M.S.S. et al. Expectativas da equipe de enfermagem em relação à liderança. Acta Paul Enferm. 2013; 26(2):198-204. Disponível em: http://www.scielo.br/scielo.php?script=sci_arttext\&pi $\mathrm{d}=$ S0103-21002013000200015\&lng=en. http://dx.doi.org/10.1590/S010321002013000200015.

SILVA, R.M; SILVA, I.C.M; RAVALIA, R.A. Ensino de Enfermagem: Reflexões Sobre o Estágio 
Curricular Supervisionado. Rev Práxis, ano I, no 1,2009. Disponível em: http://<web.unifoa.edu.br/praxis/numeros/01/37.pdf >. Acesso em: 26/02/2016.

\section{Rosângela Vidal de Negreiros}

Professora Mestre no Curso de Bacharelado em Enfermagem na Universidade Federal de Campina Grande

\section{Vanessa Cristine Batista de Lima}

Enfermeira pela Universidade Federal de Campina Grande, especialista em Unidade de Terapia Intensiva e, residente em Enfermagem Cirúrgica no Hospital das Clínicas - Recife. 